\title{
Nesnelerin İnterneti Tabanlı Akıllı Sulama ve Uzaktan İzleme Sistemi
}

\author{
Mehmet Taştan ${ }^{1 *}$ \\ ${ }^{1}$ Manisa Celal Bayar Üniversitesi, Otomasyon Bölümü, Turgutlu, Manisa, (ORCID: 0000-0003-3712-9433)
}

(İlk Geliş Tarihi 10 Şubat 2019 ve Kabul Tarihi 2 Mart 2019)

(DOI: 10.31590/ejosat.525149)

\begin{abstract}
ATIF/REFERENCE: Taştan, M. (2019). Nesnelerin İnterneti Tabanlı Akıllı Sulama ve Uzaktan İzleme Sistemi. Avrupa Bilim ve
\end{abstract} Teknoloji Dergisi, (15), 229-236.

\section{Öz}

Tarımsal ve peyzaj amaçlı sulama tatlı su kaynaklarının en çok tüketildiği uygulama alanlarıdır. Suyun akıllı yönetimi, sulama veriminin arttırılması, maliyetlerin düşürülmesi ve çevresel sürdürülebilirliğe katkıda bulmaktadır. Su kullanımını optimize etmek, enerji tüketimini azaltmak ve mahsullerin kalitesini artırmak için sulama alanında teknoloji kullanımına olan ihtiyaç her geçen gün artmaktadır. Nesnelerin İnterneti (IoT) tabanlı akıllı sulama sistemleri, tatlı su kaynaklarının verimli kullanımına yardımcı olabilir. Çevresel koşulların izlenmesi, sulama veriminin arttırmasında en önemli unsurdur. Bu çalışmada, IoT tabanlı bir akıllı sulama sistemi önerilmiştir. Önerilen bu akıllı sulama sistemi, hava sıcaklığı, hava nemi ve toprağın nem değerini kullanarak uygun sulama zamanı ve sulama süresini belirlemektedir. Akıllı sulama sistemi, sensör bilgilerini kullanarak yağış tahmininde bulunup gerektiğinde sulama zamanını ötelemektedir. Geliştirilen android tabanlı kullanıcı arayüzü, sensör verileri, sulama süresi, elektrik ve su tüketimi gibi verilerin gerçek zamanlı görüntülenmesini sağlanmaktadır. Bulut sistemi üzerine kaydedilebilen sensör verilerinin analizi ideal sulama periyodu ve sulama süresinin belirlenmesinde yardımcı olmaktadır. İnsan müdehalesini en aza indiren bu akıllı sulama sistemi ile uzaktan izleme ve kontrol imkanı yanında elektrik ve su tasarrufu sağlanmaktadır.

Anahtar Kelimeler: Nesnelerin İnterneti, Ak1llı Sulama, Blynk, Android, NodeMCU, DHT22

\section{Internet of Things Based Smart Irrigation and Remote Monitoring System}

\begin{abstract}
Agricultural and landscape irrigation are the areas where fresh water resources are most consumed. Smart management of water contributes to increasing irrigation efficiency, lowering costs and environmental sustainability. In order to optimize water use, reduce energy consumption and improve the quality of crops; the need for using technology in the irrigation field is increasing day by day. Internet of Things (IoT) based smart irrigation systems can help the efficient use of fresh water resources. Monitoring environmental conditions is the most important factor in increasing irrigation efficiency. In this study, an IoT-based smart irrigation system has been proposed. The proposed smart irrigation system determines the appropriate irrigation time and irrigation period using the air temperature, air humidity and soil moisture. The smart irrigation system uses the sensor information to estimate the precipitation and, if necessary, displace the irrigation time. Developed android-based user interface provides real-time display of data such as sensor data, irrigation time, electricity and water consumption. Analysis of sensor data that can be recorded on the cloud system helps to determine the ideal irrigation period and irrigation time. With this smart irrigation system human intervention is minimized, also remote monitoring and control as well as electricity and water saving is provided.
\end{abstract}

Keywords: Internet of Things, Smart Irrigation, Blynk, Android, NodeMCU,

\footnotetext{
*Sorumlu yazar: Manisa Celal Bayar Üniversitesi, Otomasyon Bölümü, Turgutlu, Manisa, ORCID: 0000-0003-3712-9433, mehmet.tastan@cbu.edu.tr
} 
European Journal of Science and Technology

\section{Giriş}

$\mathrm{Su}$, dünya nüfusuna gıda güvenliğini sağlamada hayati öneme sahiptir. Tarımsal sulama, tatlı su tüketiminin \%70'ini oluşturan en büyük su tüketicisidir. Ülkemiz su zengini bir ülke olmadığı gibi kişi başına düşen yıllık su miktarına göre su kitlığı yaşamaya aday bir ülke konumundadır. Su kıtlığı, günümüz tarımının başlıca problemlerinden biridir. Bu problemin üstesinden gelmenin en gerçekçi çözümü şüphesiz mevcut kıt kaynakların en verimli şeklide kullanımıdır. Ülkemizde su tüketiminin en fazla olduğu tarım sektörü \%73'lük bir kullanım payına sahiptir. Tarımsal sulamanın büyük bir bölümünün geleneksel yöntemler ile gerçekleşmesi, damla veya yağmurlama sulama gibi modern yöntemlerin az kullanımı su kaynaklarımızın verimsiz tüketimine neden olmaktadır (Sertyeşilışık, 2017).

Akıllı sulama sistemleri ile tarım arazilerinin verimli bir şekilde sulanması sağlanabilir. Akıllı sulama sistemlerinde, su tüketiminin azaltılmasının yanında ürün kalitesinin arttırılması da temel amaçlar arasındadır (Xiao ve ark., 2010). Tarımsal ve bahçe sulama sistemlerinde son y1llarda kullanımı artan programlanabilir cihazlar, günün belli saatlerinde istenen süre kadar otomatik sulama işlemi gerçekleştirmektedir. Fakat otomatik sulama sistemleri her zaman verimli sulama gerçekleştiremez.

Zaman programına dayalı otomatik sulama sistemlerinde toprağın suya ihtiyacı olup olmadığı dikkate almaz. Bazen gerçekleşen bir sulamanın hemen arkasından yada sulama öncesinde yağışın olması aşırı sulamaya neden olabilir. Bu nedenle, toprak su durumunu ölçen nem sensörlerinin kullanımı, tarımsal ve bahçecilik sulama uygulamalarında önemli bir tamamlayıcıdır (Cardenas-Lailhacar ve Dukes 2010; Soulis ve ark., 2015). Akıllı sulama, toprağın suya ihtiyaç duyduğu zaman ve ihtiyacı olduğu kadar su verilmesi işlemidir. Akıllı sulamada hava durumu, bitkilerin su ihtiyaçlarını tahmin ederek sulama yapmak için kullanılan temel faktörlerden biridir. Bulanık karar verme sistemleri kullanılarak yerel iklim verilerine dayalı toprağın su ihtiyacı tahmin edilebilmektedir (Allen ve ark., 1998). Hava durumu bilgilerine dayanarak, yapay sinir ağları yardımıyla toprağın su ihtiyacını belirlenebilmektedir (Adeloye ve ark., 2012). Fakat tek başına hava durumu tahminine dayanan sulama modelleri açık çevrim yapıya sahiptir (Giusti ve Marsili 2015). Hava durumu ve toprak nemi gibi parametreleri birlikte kullanarak oluşturulan akıllı sulama sistemleri, diğer geleneksel yaklaşımlardan daha verimli bir sulama potansiyeline sahiptir. Akşam saatlerinde veya gece yapılan sulamalarda, gündüze göre toprağın 1sısı düşük olduğundan buharlaşacak su miktarı da azalır. Böylelikle bitkiler bir sonraki günün sıcağından kendilerini yeterli miktarda su alarak korumuş olur. Bu bakımdan akıllı sulama sistemlerinde toprak nemi ve hava koşullarının yanında sulama zamanı da çok önemlidir (Kamienski ve ark., 2019). Akıllı sulama sistemlerindeki talep artışı, bu sektörü dinamik ve sürekli gelişen bir teknoloji alanı haline getirmiştir (Lichtenberg ve ard., 2013). Sensörlere dayalı sulama, su tüketimini önemli ölçüde azaltabilir ve zamanlayıcı bazlı sulama sistemleriyle kıyaslandığında genel su tüketim miktarını azaltabilir. Kablosuz sensörler kullanarak sulama yapan ABD'deki bazı süs bitkileri üreticilerinin ortalama su kullanımını yaklaşık \% 50 oranında düşeceği tahmin edilmektedir (Majsztrik ve ark., 2013). Bir sulama sistemi üreticisi tarafından geliştirilen toprak sensörlü akıllı sulama sisteminde, kendi kendine öğrenebilen sulama algoritmasını kullanmaktadır. Sensörlerden gelen bilgiler bu algoritmada işlenerek toprağın ihtiyacı olan su miktarı anlık olarak hesaplanabilmektedir (Koubachi Company, 2015). Başka bir çalışmada toprağın PH değeri, sıcaklık ve nem seviyelerini izleyen arduino tabanlı akıllı sulama sistemi gerçekleştirilmiştir (Parameswaran ve Sivaprasath 2016). IoT fiziksel nesnelerin birbirleriyle veya daha büyük sistemlerle bağlantılı olduğu bir iletişim ağıdır. Bu ağ, günlük hayatta kullandığımız çok farklı cihazlardan elde edilen milyarlarca veriyi toplayıp, kullanılabilir bilgilere dönüştürür (Gubbi ve ark., 2013).

IoT ilk olarak 1999 yılında Kevin Ashton tarafindan ortaya atılan bir terimdir. İlk başlarda RFID etiketleri sayesinde radyo frekansı üzerinden birbirleriyle haberleşen cihazları kapsayan bu konsept gelişen teknoloji ile birlikte çok daha geniş bir vizyona ulaştı (Ashton 2009). Günümüzde dünyada birbiri ile etkileşimli olan yaklaşık 20 milyar cihaz varken, 2025 yılına gelindiğinde 75 milyar cihaza çıkması tahmin edilmektedir (Evans 2011). Buda gösteriyor ki önümüzdeki yıllarda IoT ile yaşadığımız şehirler, daha tempolu ve planlı yaşama ayak uyduran akıllı şehirler hanine dönüşecektir (Zanella ve ark., 2014).

Bu çalışmada akıllı şehirlerin bir parçası olan akıllı tarım uygulamalarına bir örnek olarak, IoT tabanlı bir akıllı sulama sistemi önerilmiştir. Önerilen sistemin donanım kısmında, 32 bitlik işlemciye sahip WiFi modül içeren bir IoT denetleyicisi olan ESP826612E (NodeMCU), toprak nem sensörü, hava sıcaklı̆̆ ve nemini ölçen DHT22 dijital sensör kullanılmıştır. Yazılım kısmında, Blynk iOS/Android uygulama geliştirici ile android cihazlar için bir kullanıcı arayüzü oluşturulmuştur. Android arayüz akıllı sulama sistemi ile ilgili tüm sayısal verileri gerçek zamanlı olarak görüntüler ve Blynk Bulut alt yapısı sayesinde depolayabilir.

Önerilen bu akıllı sulama sistemi, toprak nem sensörü ile toprağın nem değerini sürekli takip ederek sulama zamanını ve toprağın ihtiyaç duyduğu su miktarını belirlemektedir. Sistem ayrıca hava şartlarını gözeterek yağı̧ beklentisi durumunda sulama zamanını ötelemektedir. Hava sıcaklı̆ğının $4^{\circ} \mathrm{C}^{\prime}$ nin altına düştüğü durumlarda don olayına karşı sulama periyodu sistem tarafindan iptal edilmektedir. Tüm bu sensör verilerini kullanan akıllı sulama sistemi, insan müdahalesine ihtiyaç duymadan sulama işlemini gerçekleştirmekte, bunun yanında su ve elektrik tüketiminin maksimum düzeyde optimizasyonunu sağlamaktadır.

\section{Materyal ve Metot}

Akıllı sulama sistemi için, gömülü mimarisi ve WiFi modüle sahip NodeMCU mikrodenetleyicisi kullanılmıştır. Ortama ait sıcaklık ve nem bilgileri, DHT22 sıcaklık-nem sensörü tarafından alınmıştır. Toprağın su ihtiyacının belirlenmesinde en büyük parametre toprağın nem değeridir. Uygulamada toprak nem değerinin ölçülmesi için analog çıkışa sahip HL-69 toprak higrometre nem sensörü kullanılmıştır.

NodeMCU; dahili WiFi özelliğiyle modüler bir yapıya sahiptir. Programlanabilir özelliği sayesinde IOT uygulamalarını düşük maliyet ile gerçekleştirebilmektedir. Dijital Giriş/Çıkış birimleri, PWM çıkışları ve haberleşme desteği sunmaktadır. NodeMCU denetleyicisine ait pin yapısı Şekil 1'de görülmektedir. 


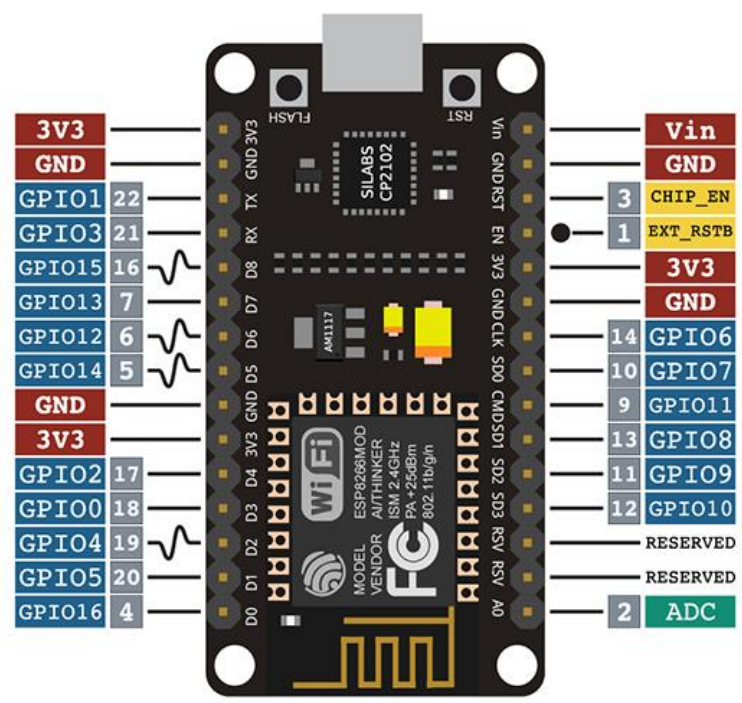

Şekil 1. NodeMCU'nun pin yapisl.

NodeMCU, çok yaygın kullanımı olan, gömülü WiFi modüle sahip bir IoT denetleyicisidir. 160 MHz'de çalışan 32 bitlik bir RISC Tensilica LX106 mikrodenetleyicisi içerir. NodeMCU'yu programlayabilmek için C++ dili kullanılmıştır. NodeMCU mini USB portu sayesinde direk olarak programlanabilirken, Şekil 1'de NodeMCU 'ya ait pin yapısı ve, Tablo 1'de ise denetleyiciye ait teknik özellikler görülmektedir.

Tablo 1. NodeMCU'nun teknik özellikleri

\begin{tabular}{cc}
\hline Özellikler & Değer \\
\hline MCU & 32 bit Tensilica L106 \\
Işlemci Frekansı & $80 / 160 \mathrm{MHz}$ \\
Input/Output & $13 x \mathrm{DIO}$ \\
ADC Pin & $1 \times 10$ bit $(1 \mathrm{~V})$ \\
Çalışma Gerilimi & $3.0 \sim 3.6 \mathrm{~V}$ \\
Çalışma Akımı & $12-200 \mathrm{~mA}$ \\
Program Hafizası & $4 \mathrm{MB}$ \\
WiFi & IEEE $802.11 \mathrm{~b} / \mathrm{g} / \mathrm{h}$ \\
Sleep Mode Akım & $<10 \mathrm{AA}$ \\
Standby Mode Akım & $<10 \mathrm{~mA}$ \\
\hline
\end{tabular}

NodeMCU denetleyicinin sahip olduğu ADC giriş pini 1V-10 bit dönüşüm yapabilmektedir. Sensör çıkışı maksimum değeri 5V olduğu için gerilim bölücü devre kullanılarak çıkış değeri 1V'a düşürülmüştür.

DHT-22, kapasitif nem ve termistör sıcaklık sensörü olmak üzere iki k1sımdan meydana gelmektedir. DHT22 sıcaklık ve nem algılayıcı, kalibre edilmiş dijital sinyal çıkışı veren gelişmiş bir sensör birimidir. Üzerinde 8 bitlik mikrodenetleyici bulunmaktadır ve kısa tepki süresine sahiptir. Hassas bir kalibrasyona sahiptir ve kalibrasyon katsayısı OTP hafızada bir çeşit program üzerinde saklanmıştır.

Ürün algılama sırasında hafizada saklı olan bu katsayıya başvurur. -40 ile $80^{\circ} \mathrm{C}$ arasında $\pm 0.5^{\circ} \mathrm{C}$ hata payı ile sicaklık, $0-100 \%$ $\mathrm{RH}$ arasında $\pm 2 \% \mathrm{rH}$ hata payı ile nem ölçümü yapabilmektedir. Modül üzerindeki MCU ile sicaklık ve nem ölçen birim (AM2302) arasında iletişim, 1 hatlı bus ile sağlanır.

\begin{tabular}{|cc|}
\hline \multicolumn{2}{|c|}{ DHT22 pins } \\
\hline 1 & VCC \\
2 & DATA \\
3 & NC \\
4 & GND \\
\hline
\end{tabular}

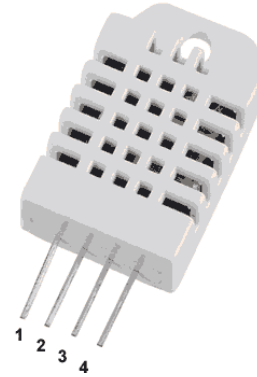

Şekil 2. DHT22 Sensörüne ait pin yapısl ve teknik özellikleri 
MCU'ya iletilen data; 16 bitlik nisbi nem, 16 bitlik sıcaklık ve 8 bitlik sağlama değeri olmak üzere 40 bitten oluşur. Vcc ile çııı̧ pini arasında $4.7 \mathrm{~K}$ ile $10 \mathrm{~K}$ arasında bir pull-up direncine ihtiyaç duyulmaktadır. Şekil 2'de DHT22 Sensörüne ait pin yapısı görülmektedir.

DHT22'den gelen nem ve sıcaklık bilgisini taşıyan sayısal sinyaller, mikrodenetleyiciler tarafindan kolayca okunabilmektedir. Hem sıcaklık hem de nem değerini yüksek hassasiyetle ölçmesi sebebiyle akıllı ev otomasyonu uygulamaları başta olmak üzere birçok nem ve sıcaklık ölçüm temelli uygulamada sıklıkla kullanılmaktadır. HL-69 higrometre nem sensörü, üzerinde LM393 komperatör bulunan yükselteç ve karşılaştırma devresi ile toprağın nem durumuna göre direnç değerini değiştiren algılayıcı devreden meydana gelmektedir. Toprağa yerleştirilen algılayıcı kısım, üzerinde bakır yollar bulunan basit bir yapıya sahiptir. Toprağın nem duruma göre direnç değeri değişir ve bu değişim miktarı toprağın nem değerini verir. Yükselteç devre, algılayıcıdaki bu direnç değişimini gerilim değişimine dönüştürür. Böylelikle toprak nem miktarına bağlı doğrusal bir analog çıkış sinyali elde edilmiş olur.

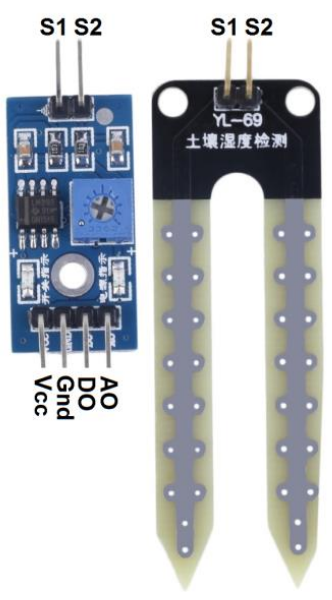

\section{Şekil 3. HL-69 Toprak Higrometre Nem Sensörü}

Sensör ayrıca kartın üzerinde bulunan trimpot ile çıkış hassasiyeti ayarlanabilen bir de dijital çıkışa sahiptir. Bu çıkış istendiğinde herhangi bir denetleyiciye ihtiyaç duyulmadan ayarlanan bir nem değerinde sulama sistemini aktif hale getirebilmektedir. Akıllı sulama sistemi uygulamasında bu çıkış kullanılmamıştır. Şekil 3'de toprak nem sensörü ve devre kartı görülmektedir. Kart üzerinde bulunan S1-2 pinleri sensör giriş, Vcc-Gnd besleme, DO dijital çıkış ve AO analog çıkış uçlarıdır. Kartın besleme gerilimi $5 \mathrm{~V}$ olup çıkışından nem değerine bağlı olarak 0-5V arasında analog çıkış vermektedir.

Blynk; Arduino, Raspery Pi, ESP32, NodeMCU gibi denetleyicilerin internet üzerinden kontrol edilmelerini sağlayan iOS ve Android uygulamaları için geliştirilmiş bir IoT platformdur.
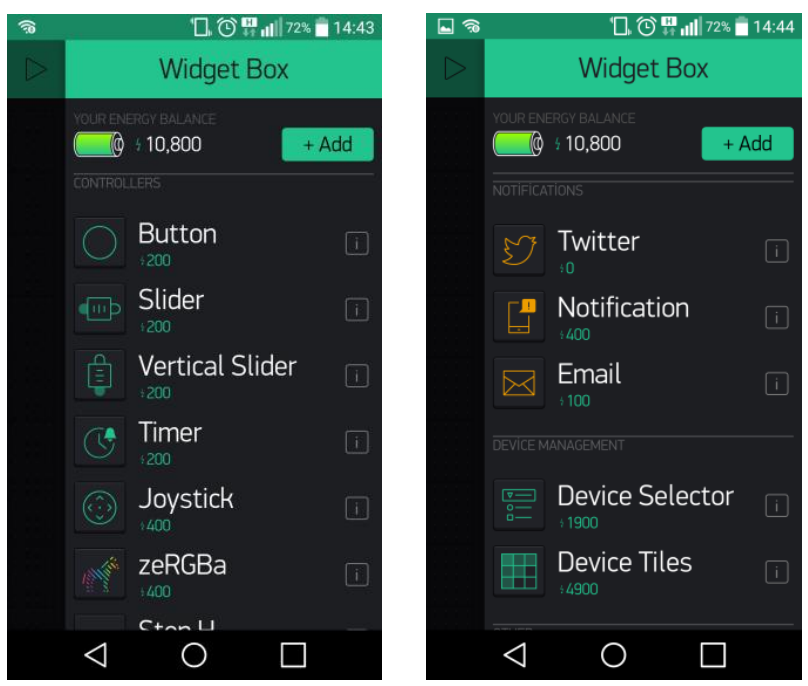

Şekil 4. Blynk Arayüz geliştiriciye ait Widget Box'lar.

Bu platformda bulunan widgetleri kullanarak IoT projeleri için bir kullanıcı arabirimi geliştirilebilmektedir.

Şekil 4'de Blynk'e ait bazı widget box'lar görülmektedir. Bu widget'lerin bazıları timer, display, joystick, gauge, e-mail, twitter, GPS'dir. Blynk, Arduino, chipKIT, ESP, Intel, LeMarker, Onion Omega, Rasperry Pi, SparkFun, STM32 gibi farklı bir çok denetleyici ile uyumludur. 
Bunlardan ESP32 gibi bluetooth özelliğine sahip denetleyicilerin bu özellikleri kullanılarak çevrim içi düşük enerji tüketerek kapalı devre iletişim sağlanabilmektedir. Tüm bu özellikleri sayesinde Blynk; IoT geliştiricileri için düşük ücretli çözümler sunmakta ve bu kullanıcılar aynı zamanda bulut hizmetinden de yaralanabilmektedir.

\section{Bulgular ve Tartışma}

Akıllı sulama için gerçekleştirilen sistemin genel yapısı Şekil 5'de görülmektedir. Sistem genel olarak sırasıyla; 32 bitlik dahili WiFi modüllü NodeMCU denetleyicisi, DHT22 sıcaklık-nem sensörü, HL-69 higrometre nem sensörü, denetleyicinin çıkış pini üzerinden selenoid vanaların kontrolünü sağlayan röle modülü, "Akıllı Sulama" Android kullanıcı arayüzü, Blynk server ve Blynk Bulut sisteminden oluşmaktadır.

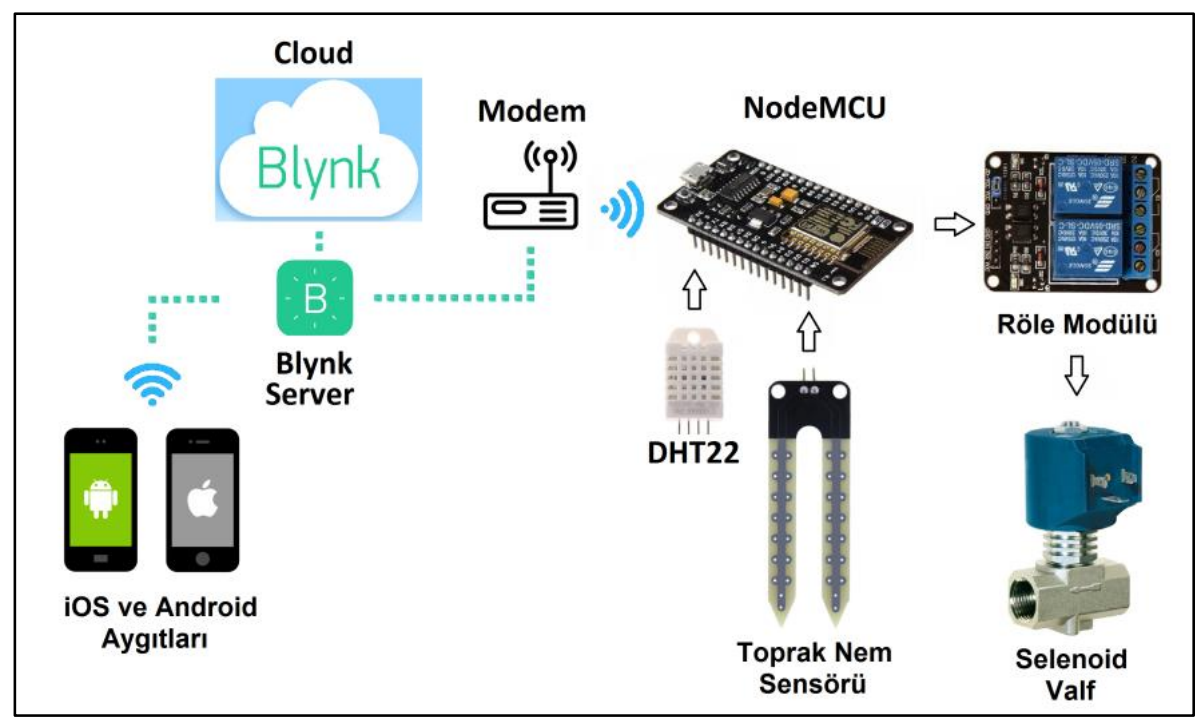

Şekil 5. Android tabanlı akall sulama sistemin yapıst.

NodeMCU denetleyicisi için sistem gereksinimlerini karşılayacak kod C++ dili kullanılarak Arduino IDE editöründe yazılmıştır. NodeMCU, DHT22'den ve HL-69 higrometre nem sensöründen aldığı sıcaklık ve nem değerlerini her 5sn'de Blynk server'a göndermektedir. Blynk uygulamasında, display, terminal gibi widgetler ile 10 bitlik veri tranferi sağlayan 128 adet sanal pin bulumaktadır. DHT22 ve HL-69 higrometre nem sensörlerinden alınan verilerin NodeMCU üzerinden Blynk server'a gönderilmesine ait kod bölümü Şekil 6'da görülmektedir. Burada V3, V5 ve V7 sanal pinleri PR1, PR2 ve PR3 zaman programına ait durum ledlerini kontrol etmektedir. Aktif programı gösteren led için sanal pinler üzerinden 1023 bilgisi gönderilerek uygulama üzerinde ledin yeşil renkte yanması sağlanmaktadır. V11 pini, sulama sisteminin manuel olarak çalıştırıldığı durumda sistemin çalışma bilgisini Blynk uygulamasına gönderir. V0 toprak nemini, V8 havanın nemini, V9 hava sıcaklığını, V12 su tüketim miktarını ve V13 elektrik tüketimini Blynk uygulamasına aktaran sanal pinlerdir.

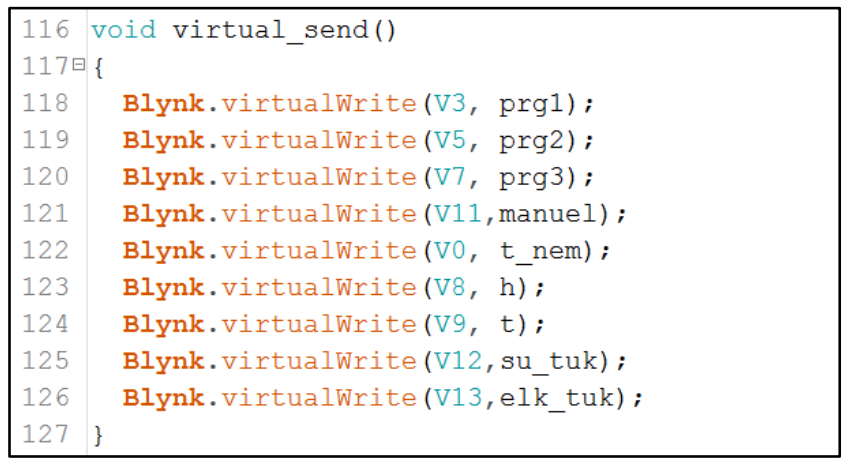

Şekil 6. Sayısal değerlerin Blynk uygulamasına sanal pinler üzerinden gönderilmesine ait kod bölümü. 


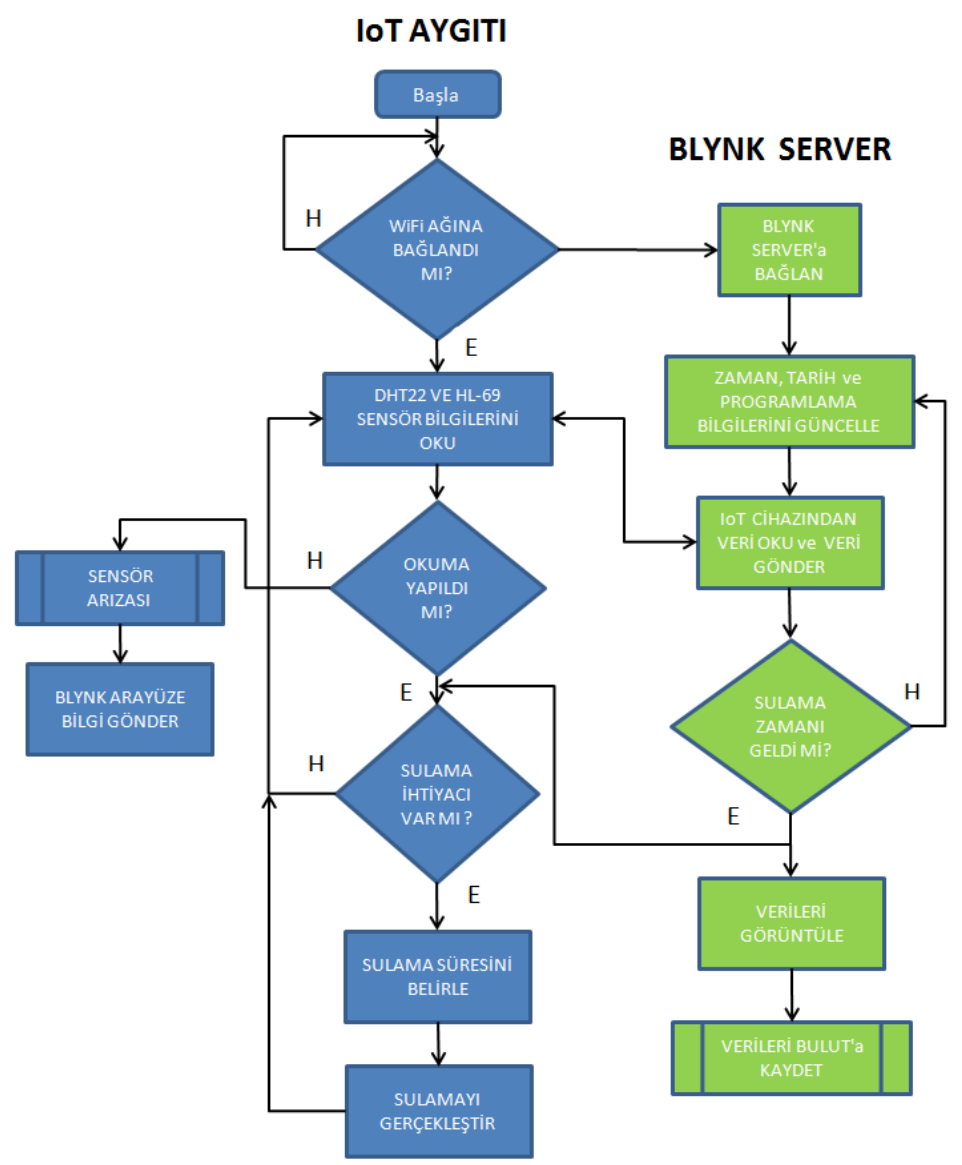

Şekil 7. "AKILLI SULAMA" sistemine ait akış diyagramı.

Şekil 7'da "Akıllı Sulama" sistemine ait akış diyagramı görülmektedir. "Akıllı Sulama" arayüzü Blynk serverdan belirli aralıklarla sistemle ilgili sayısal bilgileri almaktadır. Şekil 8'de "AKILLI SULAMA" kullanıcı arayüzüne ait uygulama pencereleri görülmektedir. Şekil 8a'daki pencerede toprak nem sensöründen alınan veriler, zaman program ayarları, manuel çalıştırma butonu, toprak nemi alt değeri, tarih-saat bilgileri, WiFi sinyal seviyesi ve nem-zaman grafiği görülmektedir. Şekil 8b'deki kullanıcı penceresinde twitter ve e-mail bildirim witgetleri, hava sıcaklığı-nemi, su ve elektrik tüketimi bilgileri görüntülenmektedir.

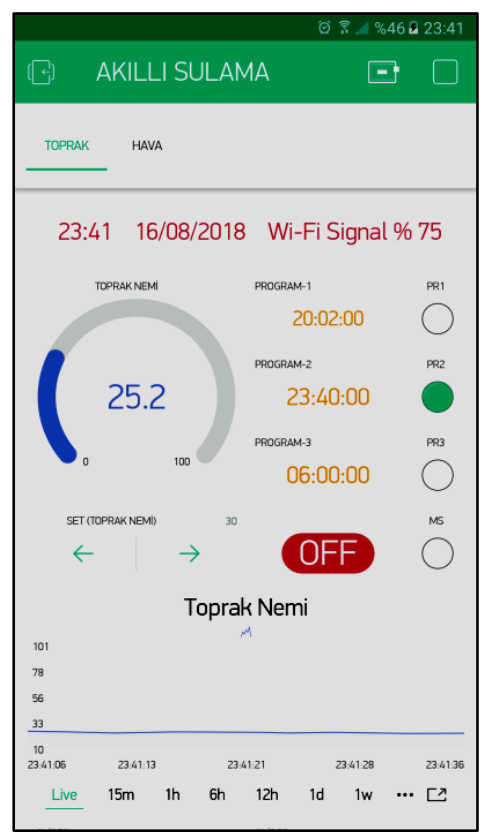

(a)

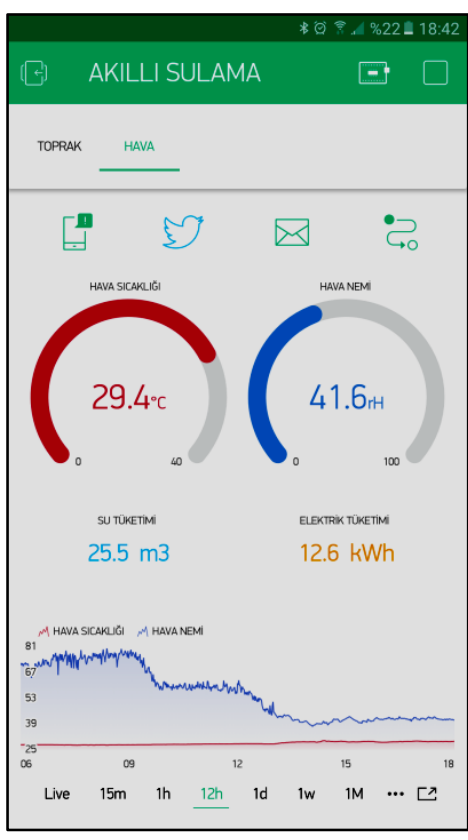

(b)

Şekil 8. "AKILLI SULAMA" arayüze ait pencereler a) Toprak ölçümü b) Hava Ölçümü verileri. 
Sulama işlemi için 3 ayrı programlama seçeneği bulunmaktadır. Bu seçenekler için ayrı ayrı başlatma ve durdurma zamanları ayarlanabilmektedir. Programlanan zaman dilimi aktif olduğunda toprak nemi ayarlanan limit değerin altında ise ve yağış yoksa bu durumda sulama

işlemi ayarlanan süre kadar yapilir.
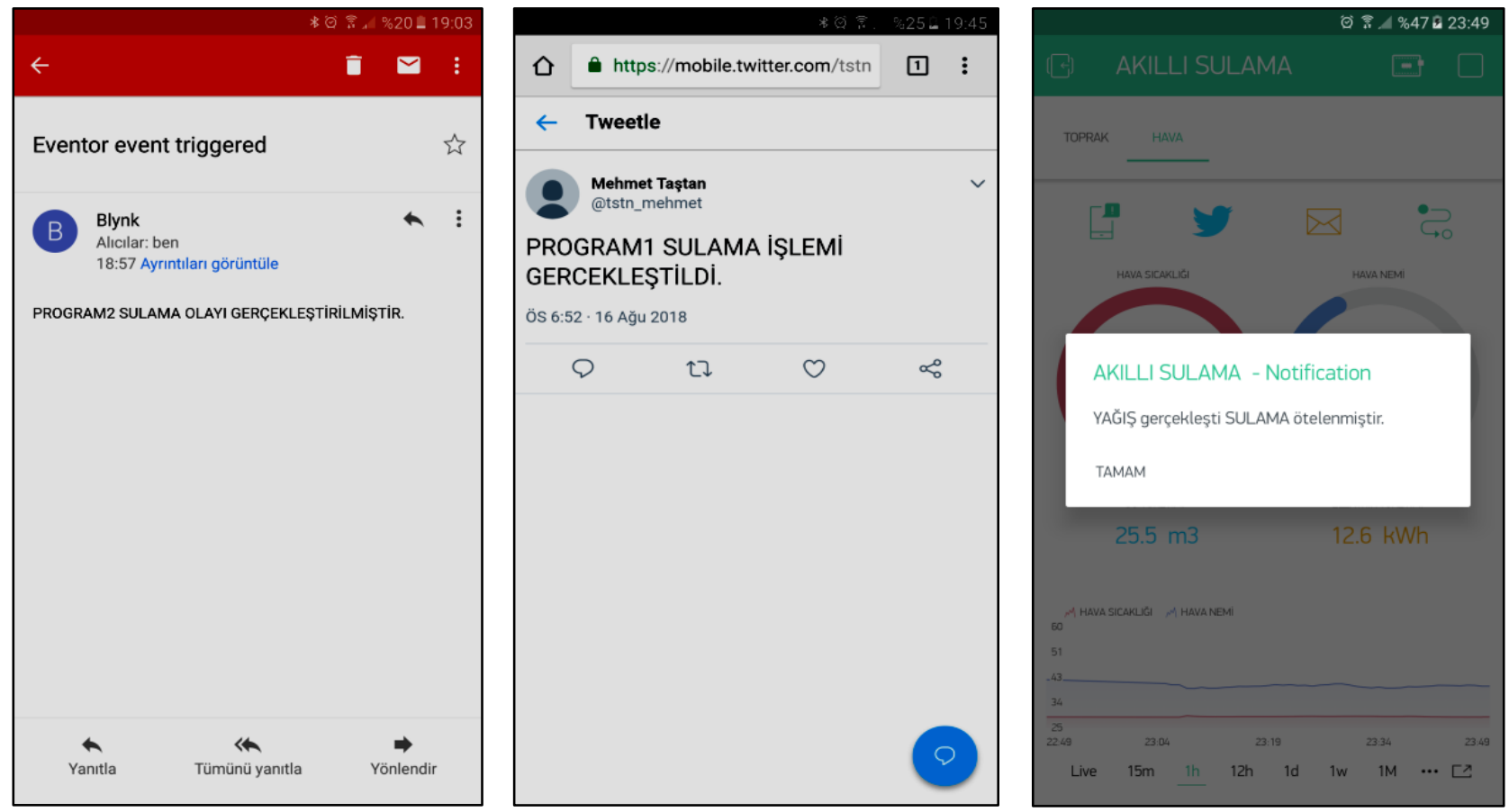

Şekil 9. "AKILLI SULAMA" arayüze ait, a) e-mail bildirimi , b) twitter bildirimi c) uygulama bildirimi.

DHT22 sensörü verilerine göre denetleyici yağış tahmininde bulunursa bu durumda sulama işlemi iptal edilerek bir sonraki programın aktif olması beklenir. Şekil 9'de görüldüğü gibi uygulama belirlenen e-mail veya twitter hesaplarına bildirim gönderebilmektedir. Şekil 9a'da Program-2 'nin aktif olduğunu ve sulama işleminin tamamlandığını gösteren bir e-mail bildirimi, Şekil 9b'de program-1'deki sulama işleminin gerçekleştiğini ifade eden bir twitter bildirimi Şekil 9c'de bir yağışın gerçekleştiğini ve sulama işleminin ötelendiğini ifade eden uygulama ekranı üzerinden kullanıcıya aktarılan bildirim görülmektedir. Yağış gerçekleştiğinde toprak nemindeki artış en yakın sulama zamanının ötelenmesine neden olmaktadır. Bu şekilde toprağın aşırı sulanmasının önüne geçilerek gereksiz su teketimide engellenmiş olmaktadır. Sulama periyotları suyun buharlaşmasının minimum değerde tutulması için özellikle gece saatlerinde olacak şekilde seçilmektedir.

\section{Sonuç ve Öneriler}

İnternet teknolojisi üzerinden birçok hizmetin verildiği günümüzde, bu altyapıyı kullanan uygulamaların sayısı sürekli olarak artmaktadır. İnsanların artarak devam eden konfor düşkünlüğü, kendi işini yapabilen akıllı ve otonom cihazlara olan talebin de sürekli artmasına neden olmaktadır. Artık internet; sosyal medya araçları, e-ticaret platformu, haber kaynağı gibi fonksiyonlarının yanında, bize çok farklı imkânlar sunarak gelecekle ilgili beklentilerimizi de sürekli olarak değiştirmektedir. Hayatımızda yeni bir dönem başlatan IoT kavramı, her geçen gün genişleyerek farklı sektör ve uygulamaları bünyesine dâhil etmektedir.

Bu çalışmada dahili WiFi modüle sahip NodeMCU denetleyicisi kullanılarak bir akıllı bahçe sulama sistemi gerçekleştirilmiştir. Havanın sıcaklık ve nem değeri ile beraber toprak nem değerininde ölçüldüğü bu sulama sisteminde ideal bir sulama peryodu ve sulama süresi hedeflenmiştir. Blynk platformuyla gerçekleştirilen android tabanlı kullanıcı arayüzü sayesinde akıllı sulama sisteminin internet üzerinden kontrolü ve izlenmesi sağlanmıştır. Bu arayüz sisteme ait nem ve sicaklık verilerini bulut üzerinden sürekli kayıt altına almaktadır. Elde edilen bu verilerin saatlik ve günlük değişimleri dikkate alınarak ideal sulama süresi ve sulama peryodu elde edilmiştir. Bu sulama sistemi sulama işlemini toprağın suya ihtiyaç duyduğu zamanlarda ve ihtiyacı kadar su vererek hem su hemde elektrik enerjisi tasarrufu sağlamaktadır. Sistem temelde toğrağın nem değerini dikkate aldığı için yağış durumlarında gereksiz sulama işlemininin de önüne geçilmektedir. Düşük maliyetli, hızlı ve güvenilir bir çözüm üretilen bu örnek akıllı bahçe sulama sistemi, daha büyük ölçekli sulama alanlarına uygulanarak önemli kıt kaynaklarımız arasında olan suyun maksimum verimde kullanılmasına imkan sağlayacaktır.

\section{Kaynaklar}

Adeloye, A. J., Rustum, R., \& Kariyama, I. D. (2012). Neural computing modeling of the reference crop evapotranspiration. Environmental Modelling \& Software, 29(1), 61-73.

Allen, R. G., Pereira, L. S., Raes, D., \& Smith, M. (1998). Crop evapotranspiration-Guidelines for computing crop water requirements-FAO Irrigation and drainage paper 56. Fao, Rome, 300(9), D05109. 
Ashton, K. (2009). That 'internet of things' thing. RFID journal, 22(7), 97-114.

Cardenas-Lailhacar, B., Dukes, M. D. (2010). Precision of soil moisture sensor irrigation controllers under field conditions. Agricultural Water Management, 97(5), 666-672.

Evans, Dave. "The internet of things: How the next evolution of the internet is changing everything." CISCO white paper 1.2011 (2011): 1-11.

Giusti, E., Marsili-Libelli, S., 2015. A fuzzy decision support system for irrigation and water conservation in agriculture. Environ. Model. Softw. 63, 73-86.

Gubbi, J., Buyya, R., Marusic, S., \& Palaniswami, M. (2013). Internet of Things (IoT): A vision, architectural elements, and future directions. Future generation computer systems, 29(7), 1645-1660.

Kamienski, C., Soininen, J. P., Taumberger, M., Dantas, R., Toscano, A., Salmon Cinotti, T., ... \& Torre Neto, A. (2019). Smart Water Management Platform: IoT-Based Precision Irrigation for Agriculture. Sensors, 19(2), 276.

Koubachi Company. , "The Plant Sensor for your Home and Garden", April 2015.

Lichtenberg, E., Majsztrik, J., \& Saavoss, M. (2013). Profitability of sensor-based irrigation in greenhouse and nursery crops. HortTechnology, 23(6), 770-774.

Majsztrik, J. C., Price, E. W., \& King, D. M. (2013). Environmental benefits of wireless sensor-based irrigation networks: Case-study projections and potential adoption rates. HortTechnology, 23(6), 783-793.

Parameswaran, G., \& Sivaprasath, K. (2016). Arduino Based Smart Drip Irrigation System Using Internet of Things. Int. J. Eng. Sci, 5518.

Sertyeşilışı, E. (2017). Türkiye'nin Su Kaynaklarının Ekonomi Politiği Üzerine Bir İnceleme. Türk Bilimsel Derlemeler Dergisi, 10(1), 28-30.

Soulis, K. X., Elmaloglou, S., \& Dercas, N. (2015). Investigating the effects of soil moisture sensors positioning and accuracy on soil moisture based drip irrigation scheduling systems. Agricultural Water Management, 148, 258-268.

Xiao, K., Xiao, D., \& Luo, X. (2010). Smart water-saving irrigation system in precision agriculture based on wireless sensor network. Transactions of the Chinese Society of Agricultural Engineering, 26(11), 170-175.

Zanella, A., Bui, N., Castellani, A., Vangelista, L., \& Zorzi, M. (2014). Internet of things for smart cities. IEEE Internet of Things journal, 1(1), 22-32. 